\title{
THE USE OF VIDEO-TACHEOMETRIC TECHNOLOGY FOR DOCUMENTING AND ANALYSING GEOMETRIC FEATURES OF OBJECTS
}

\author{
Marek Woźniak, Ewa Świerczyńska, Sławomir Jastrzębski \\ Faculty of Geodesy and Cartography, Warsaw University of Technology, \\ Warsaw, Poland
}

\begin{abstract}
This paper analyzes selected aspects of the use of video-tacheometric technology for inventorying and documenting geometric features of objects. Data was collected with the use of the video- tacheometer Topcon Image Station IS-3 and the professional camera Canon EOS 5D Mark II. During the field work and the development of data the following experiments have been performed: multiple determination of the camera interior orientation parameters and distortion parameters of five lenses with different focal lengths, reflectorless measurements of profiles for the elevation and inventory of decorative surface wall of the building of Warsaw Ballet School. During the research the process of acquiring and integrating videotacheometric data was analysed as well as the process of combining "point cloud" acquired by using video-tacheometer in the scanning process with independent photographs taken by a digital camera. On the basis of tests performed, utility of the use of video-tacheometric technology in geodetic surveys of geometrical features of buildings has been established.
\end{abstract}

Keywords: video-tacheometric technology, reflectorless technology, lens distortion, photogrammetry, scanning.

\section{Introduction}

The demand for 3D visualization products increases nowadays and therefore manufacturers of the surveying scanning devices deliver new, more diversified sets of surveying instruments. The main task of all newly presented surveying devices is the simplicity of data acquisition and completeness of information about an object. 3D models are generated basing on two types of data: "point clouds" containing information about the spatial location and geometric features of an object and digital images. Acquired images provide information about the colour and characteristics of selective reflection and geometric features of an object. Utilisation of different types 
of data during 3D visualisation increases the scope of knowledge about an object and the value of obtained results. On the other hand, due to the need of exterior orientation of images and registered "point clouds", the time needed for the final product delivery is increased.

Video-tacheometric technology consists of joining laser-scanning technology with digital photography in one surveying set, called a video-tacheometer. This device is used to register digital images along with "point clouds" correlated with them in respect of exterior orientation parameters in a uniform coordinate system at a stage of measurement process (Woźniak, 2005). The reflectorless survey of selected object points is enriched by digital images taken with a digital camera, built in the optical system of the device lens. After defining the scanning area, device takes a set of images representing a small part of a measured element. The image block delivered by joining all individual images, represents the entire scanning area. The results of a survey made with the use of the video-tacheometer are: observation records consisting of traditional tacheometric parameters (co-ordinates, angles, distances), as well as images from the built-in camera. All surveying data included in such a complex form may be processed with the use of software enabling spatial data and digital images elements integration (Tkaczyk, Szumowska, 2010). Due to the simple survey procedure and image processing automation it is possible to deliver several features of the inventoried object with one surveying set, inter alia its location, shape, size and colour.

The video-tacheometer delivers, in short time, "point clouds" which are geometrically integrated with digital images. The main disadvantage of this device is relatively low resolution of built-in, interior and wide-angle, exterior cameras. Individual images can be taken from surveying position. It is the advantage of the design solution, as the homogeneity of the co-ordinate system of all registered data is provided this way. In case of the use of an independent, professional digital camera we have more flexibility during taking images and we are able to register images with an exceptionally high resolution. The advantage of the use of images taken with the integrated camera is full automation of the survey process, as well as further processing of observed data. Video-tacheometric technology is based on automation of the complete process of measurements and on processing results without unnecessary interaction by the operator.

To enable a digital photograph to be used for various analyses and transformations, it is necessary to take it in the technically perfect way. This perfection is revealed in geometrical and radiometrical fidelity, compared to the original object. The technically perfect photograph includes much more information of much higher quality, which can be used during its transformation process. The image quality depends also on conditions and the object behaviour during the registration and it is a complex surveying process from the photogrammetric perspective (Piasecki, 1958).

Depending on the conditions during acquisition of photographs of an object and on the further possible applications of acquired images, several basic parameters of exposure, which affect directly the image quality, must be correctly set. Among them the most important are: exposure time, the lens aperture number, photosensitivity of the image-registering matrix and the type of light used to illuminate an object, i.e. light colour described by the colour temperature (Owczarz, 2004). These elements are the basis for determination of the image registering camera settings. The task for photosensitive layer of the projection matrix is reconstruction of object luminance features in the correct colour scale. The contrast of object surface depends on ratio 
of the lowest and the highest illuminance. It has a direct impact on the resolution of the registered image. Similarly, the lens and the matrix optical resolving power have a direct impact on the resultant image resolution and sharpness of registered object projection.

The parameter, which is essential for image quality, is distortion, defined as a defect of the optical system. It results in a change of the image zoom depending on the distance from the camera optical axis. The distortion causes an error of image object representation as central projection. The distortion is treated as a structural feature of the lens, which causes "a shift of image points" (Sitek, 1991). There are two types of distortion: radial (symmetrical) and tangential (asymmetrical) distortion. The first type of distortion is caused by changes of refraction of lenses set and the second type of distortion is caused by inclinations and decentralization of lens optical elements. Shifts of image points comparing to their theoretical locations can be decomposed into two components: the radial component (directed along the radial radius) and the tangential component (perpendicular to this radius) (Bernasik, 2006). Contemporary photogrammetric cameras are equipped with very good lenses with distortion error not bigger than a few microns. The worse situation occurs in case of digital photographic cameras, where impact of this defect can reach a level of tens of pixels (Bernasik, 2006). So, there is a necessity to correct this defect of the optical system, aiming at improvement of the geometrical quality of products derived with the use of digital images.

\section{Experimental measurements with the use of video-tacheometric technology}

The main objective of performed research was the evaluation of usefulness and effectiveness of utilisation of video-techeometer technology for documentation and analyses of geometric features of objects. During the research, the process of acquiring and integrating video-tacheometric data (images and "point clouds") was analysed, as well as the process of integration of data acquired by using videotacheometer with images taken by an independent digital camera.

Research works were divided into three experimental tasks:

- interior orientation parameters of Canon EOS 5D Mark II camera determination along with distortion parameters of five lenses with different focal lengths, in different work conditions,

- reflectorless, elevations profile measurement with video-tacheometer Topcon Image Station IS-3 (the main parameters: camera resolution - 4.8 megapixels; accuracy of reflectorless distance measurement - from $1.5 \mathrm{~m}$ to $250 \mathrm{~m}$ : $+/-5 \mathrm{~mm}$, above $250 \mathrm{~m}:+/-(10 \mathrm{~mm}+10 \mathrm{~mm} / \mathrm{km})$; angle measurement accuracy - 3"),

- surface spatial inventory for one of the walls of Warsaw Ballet School aiming at 3D model generation based on data collected with videotacheometer Topcon Image Station IS-3 and images taken with Canon EOS 5D Mark II camera. 


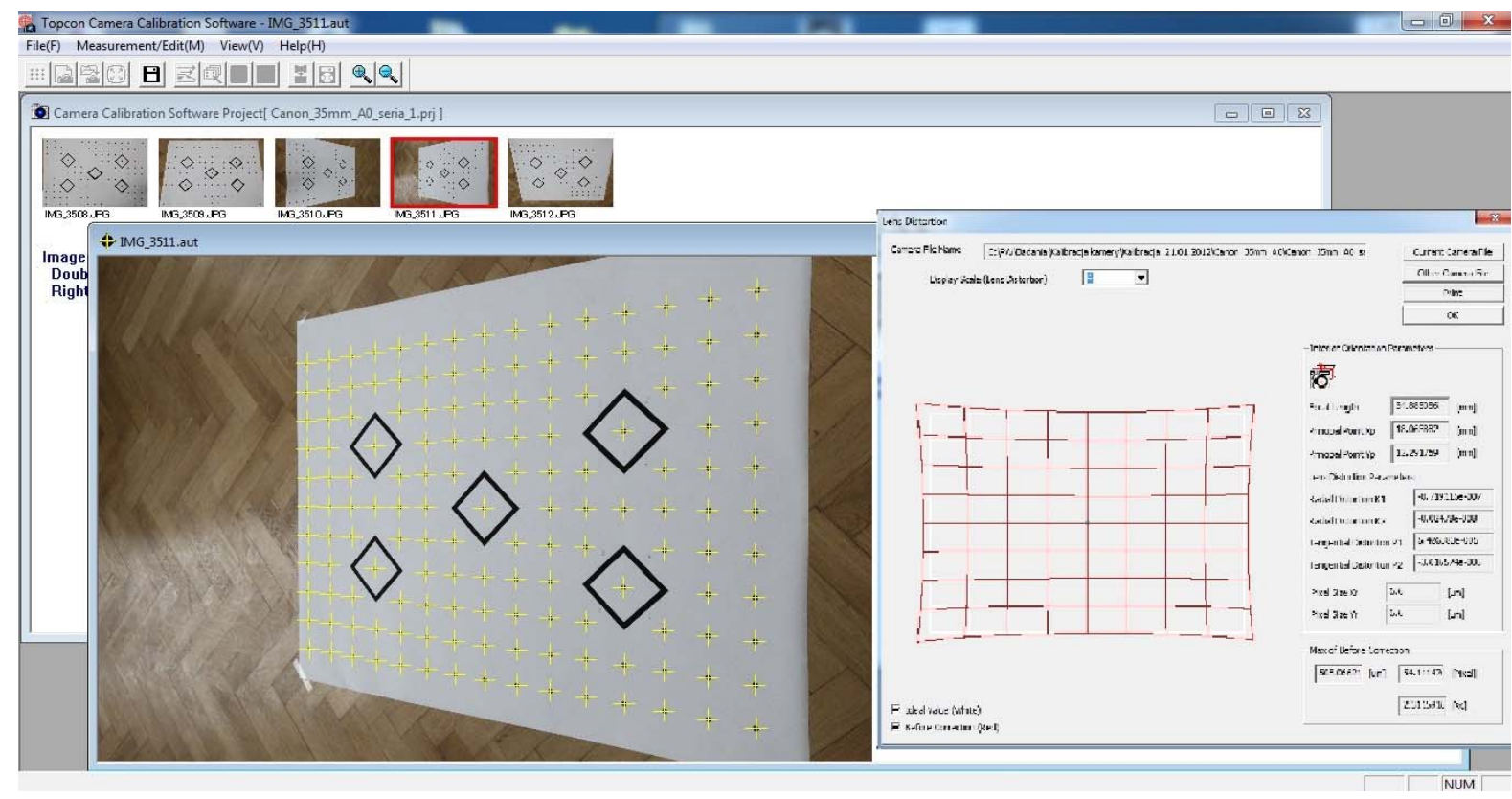

Fig. 1. Dialog box of the software performed using Topcon Image Master Calib for a set of five images of the test field

The first task was the multiple determinations of interior orientation parameters of the camera and radial and tangential distortion of the lens with the use of the same pattern of the test field. The objective of this experiment was to determine the repeatability of calibration process, starting with "calibration" image registration and ending with determination of relevant values of derived parameters. Thanks to storing the radial and tangential distortion function for a given camera-lens sets, the proper transformation of registered images is possible. There are different ways to introduce the distortion correction i.e. interpolation, tabular and polynomial methods. Due to the utilisation of "camera calibration" parameters for correction of many images taken with this camera, it is necessary to multiply determine camera parameters, to eliminate errors of this process and to improve reliability of the calibration process. Nowadays, existing programmes for photogrammetric image processing have various models of distortion implemented. Apart from software properties, the most important condition of calibration process is registration of calibration images with identical camera settings as ones applied during acquisition of images of the calibration sheet, taken from different camera positions, relative to the test field. Camera interior orientation parameters and imaging deformation parameters are calculated iteratively, basing on co-ordinates of matching points, taken from every calibration image, with the use of the collinearity equation. Multiple determinations of interior orientation and distortion parameters were performed with the use of Image Master Calib software. The results of this process were used during integration of images taken with Canon EOS 5D Mark II camera with the "point cloud".

To evaluate the repeatability of results of the video-techeometer Image Station IS-3 scanning process during examination of geometric features of objects, several measurements of profiles of three columns located in the Main Auditorium of the Warsaw University of Technology were performed (Fig. 2). To avoid an object outline identification error, a very "simple" object surface has been chosen for this experiment. For all surveying series, an identical scanning area was defined with the use of two different optional scanning functions: LINE (scanning along the line) and AREA (scanning area of a polygon). 


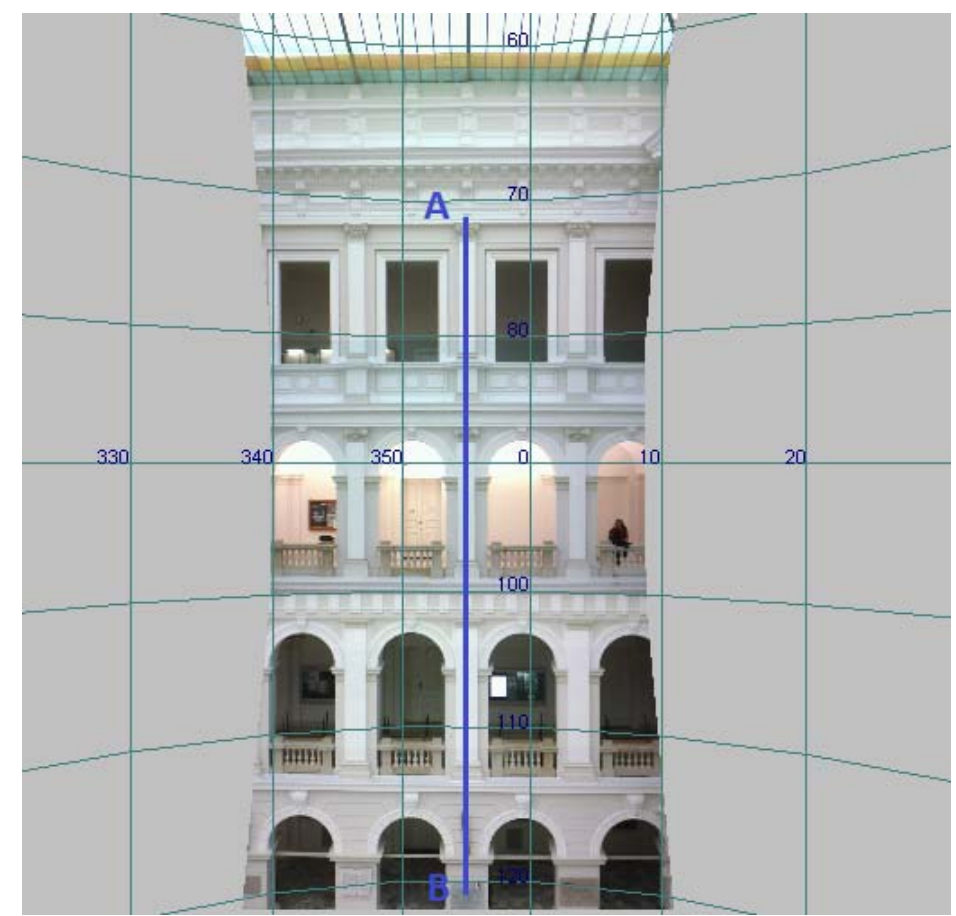

Fig. 2. The projection of the registered image from the video-tacheometer stretched on a spherical surface - dialog window of the Image Master

The measuring station was localised in such a way, that the device's line of sight "crossed" in the horizontal plane the surface of the column under the approximately 90 degrees angle. The examined $A B$ profile was scanned for multiple times, with the different scanning resolution: four series - 15 points $/ \mathrm{m}^{2}$ (distance between two points was $0,25 \mathrm{~m}$ ) and with ten times bigger resolution, two series - $150 \mathrm{points} / \mathrm{m}^{2}$ (distance between two points was $0,08 \mathrm{~m}$ ). The same line was measured in three series with the other lens orientation and with scanning resolution of approx. 50 points $/ \mathrm{m}^{2}$ (distance between two points was $0,14 \mathrm{~m}$ ).

The last step of tests was the examination of possibility of video-tacheometer utilisation with measurement of one of the characteristic walls of the Warsaw Ballet School's building, conducted for several times in the standard scanning mode (Topcon Imaging Station IS-3 has two different scanning modes: standard scanning mode - it is continuous scan mode, and point scan mode - it is scan mode of single points). This object, as seen in Fig. 3, has a specific texture supporting detailed surface points identification.

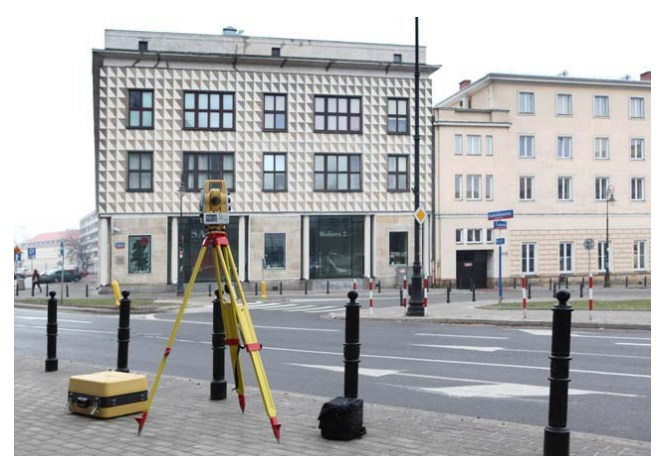

Fig. 3. The station during measurements of the building's facade of the Warsaw Ballet School 
This facade has been measured with the video-tacheometer from the station located within the distance of approx. $20 \mathrm{~m}$, with the mean scanning resolution of 60 points $/ \mathrm{m}^{2}$, which resulted in approx. 8.5 thousand of points. During the measurements, the video-tacheometer has been registering also images with two cameras: the wide-angle camera (with $33^{\circ}$ field-of-view) and the internal camera, built-in optical system of the lens, with $1^{\circ}$ field-of-view. The images were geometrically referenced as early as at the stage of acquisition, so they were spatially oriented.

\section{Results of experimental measurements}

Printouts of the calibration sheet, generated by means of Image Master Calib software package in two formats, $A 0$ and $A 3$, were used as test fields. Each of them included 5 main symbols and 145 ancillary symbols. During calibration centres of all control points were automatically searched for by the software. Thus it is necessary that all standard and ancillary marks (control points) are visible on the calibration photograph.

In order to check the repeatability of determination of the interior orientation parameters and distortion for every tested lens, two series of measurements were performed. All calibrating works were performed with the same settings of the digital camera (the photographic mode, or the white balance). Besides, the influence of nonflatness of the test field on results of the calibration process performed according to the Image Master Calib algorithm, were analysed. For two focal lengths, $50 \mathrm{~mm}$ and $35 \mathrm{~mm}$ additional series of photographs were taken, with the intentionally distorted calibration sheet, for both, the A0 and A3 formats. This aimed at testing the influence of the non-flatness of the test field on the possibility to determine the camera interior orientation parameters, according to the computational algorithm of Image Master Calib software.

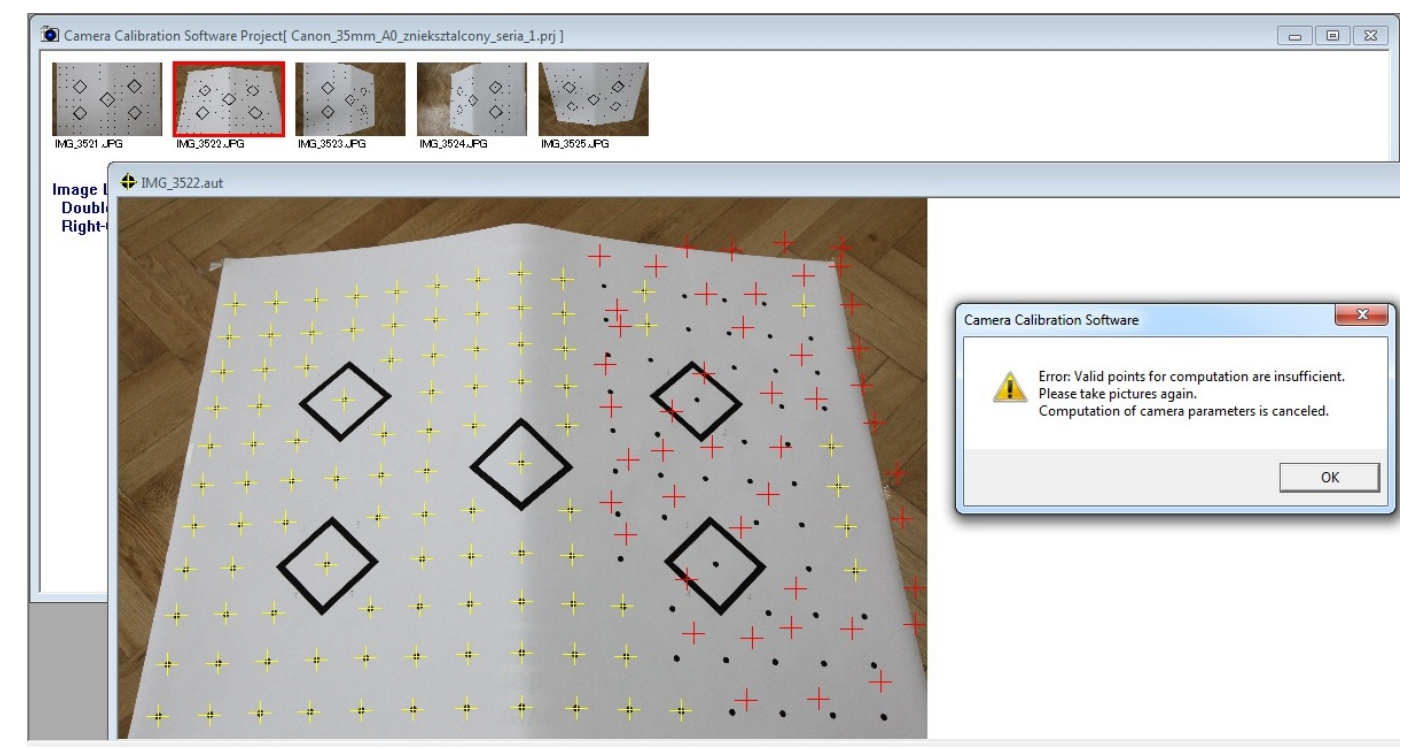

Fig. 4. Dialog box showing results of calibration realized using Topcon Image Master Calib for a set of five images of the test field 
This software package allows for automatic or semi-automatic generation of the following parameters: the lens focal length, parameters of radial distortion, parameters of tangential distortion, location of the principal point. The computational algorithm compares, first of all, co-ordinates of centres of black dots, evenly located on the test field sheet, which are recorded in the package and centres of marks, visible on calibrating photographs, recorded during measurements. Depending on the format of the calibration sheet, the software package finds appropriate points of projection.

Table 1. The results of calibration of the Canon EOS 5D Mark II using different zoom lenses

\begin{tabular}{|c|c|c|c|c|c|c|c|c|c|c|c|}
\hline \multirow{2}{*}{$\begin{array}{c}\text { Canon EOS 5D } \\
\text { Mark II camera + } \\
\text { lens: }\end{array}$} & \multirow{2}{*}{$\begin{array}{c}\text { Format of } \\
\text { the test } \\
\text { field }\end{array}$} & \multirow{2}{*}{$\begin{array}{c}\text { Series/ } \\
\text { average }\end{array}$} & \multirow{2}{*}{$\begin{array}{l}\text { Focal } \\
\text { length } \\
\mathrm{f}[\mathrm{mm}]\end{array}$} & \multicolumn{2}{|c|}{ Radial distortion } & \multicolumn{2}{|c|}{$\begin{array}{l}\text { Tangential } \\
\text { distortion }\end{array}$} & \multicolumn{2}{|c|}{ Principal point } & \multirow{2}{*}{\begin{tabular}{|c|} 
Measurement \\
accuracy \\
{$[$ Pixel $]$}
\end{tabular}} & \multirow{2}{*}{ Comments } \\
\hline & & & & $\mathrm{K} 1\left[10^{-4}\right]$ & K2 $\left[10^{-7}\right]$ & P1 $\left[10^{-4}\right]$ & P2 $\left[10^{-5}\right]$ & $\mathrm{Xp}[\mathrm{mm}]$ & $\mathrm{Yp}[\mathrm{mm}]$ & & \\
\hline \multirow{3}{*}{ Canon $20 \mathrm{~mm}$} & \multirow{3}{*}{$\mathrm{A} 0$} & 1 & 19.983 & 2.112 & -3.895 & 0.178 & 0.054 & 17.350 & 11.507 & 0.247 & \\
\hline & & 2 & 19.972 & 2.106 & -3.880 & 0.217 & -0.041 & 17.351 & 11.508 & 0.245 & \\
\hline & & average & 19.977 & 2.109 & -3.888 & 0.198 & 0.006 & 17.351 & 11.507 & 0.246 & \\
\hline \multirow{3}{*}{ Canon 35mm } & \multirow{3}{*}{ A0 } & 1 & 34.885 & -0.009 & -0.808 & 0.543 & -3.617 & 18.064 & 12.292 & 0.245 & \\
\hline & & 2 & 34.892 & 0.006 & -0.856 & 0.542 & -3.482 & 18.050 & 12.239 & 0.246 & \\
\hline & & average & 34.889 & -0.001 & -0.832 & 0.542 & -3.549 & 18.057 & 12.265 & 0.246 & \\
\hline \multirow{2}{*}{ Canon $35 \mathrm{~mm}$} & \multirow{2}{*}{$\mathrm{A} 0$} & 1 & \multirow{2}{*}{\multicolumn{8}{|c|}{ Impossible determination of orientation parameters }} & Intended \\
\hline & & 2 & & & & & & & & & the test field \\
\hline \multirow{3}{*}{ Canon $50 \mathrm{~mm}$} & \multirow{3}{*}{ A0 } & 1 & 50.178 & 0.628 & -0.144 & 0.240 & 2.015 & 17.142 & 11.007 & 0.194 & \\
\hline & & 2 & 50.191 & 0.627 & -0.134 & 0.127 & 3.069 & 17.082 & 10.777 & 0.197 & \\
\hline & & average & 50.184 & 0.627 & -0.139 & 0.184 & 2.542 & 17.112 & 10.892 & 0.196 & \\
\hline \multirow{3}{*}{ Canon $50 \mathrm{~mm}$} & \multirow{3}{*}{ A0 } & 1 & 50.215 & 0.615 & -0.122 & 0.190 & 0.439 & 17.024 & 11.448 & 0.247 & \multirow{3}{*}{$\begin{array}{c}\text { With the use of } \\
\text { a tripod }\end{array}$} \\
\hline & & 2 & 50.202 & 0.631 & -0.172 & 0.119 & 0.682 & 17.096 & 11.498 & 0.248 & \\
\hline & & average & 50.208 & 0.623 & -0.147 & 0.154 & 0.561 & 17.060 & 11.473 & 0.248 & \\
\hline \multirow{3}{*}{ Canon $50 \mathrm{~mm}$} & \multirow{3}{*}{ A3 } & 1 & 50.286 & 0.636 & 0.356 & 0.299 & -0.025 & 16.381 & 10.913 & 0.332 & \\
\hline & & 2 & 50.307 & 0.652 & 0.304 & 0.332 & -0.401 & 16.331 & 10.900 & 0.413 & \\
\hline & & average & 50.297 & 0.644 & 0.330 & 0.316 & -0.213 & 16.356 & 10.906 & 0.373 & \\
\hline \multirow{3}{*}{ Canon $50 \mathrm{~mm}$} & \multirow{3}{*}{$\mathrm{A} 3$} & 1 & 50.222 & 0.707 & 0.162 & 0.262 & -1.251 & 16.418 & 10.922 & 0.290 & \multirow{3}{*}{$\begin{array}{c}\text { Assumed } \\
\text { deformation of } \\
\text { the test field }\end{array}$} \\
\hline & & 2 & 50.204 & 0.695 & 0.217 & 0.246 & -0.918 & 16.399 & 10.990 & 0.323 & \\
\hline & & average & 50.213 & 0.701 & 0.189 & 0.254 & -1.084 & 16.408 & 10.956 & 0.306 & \\
\hline \multirow{3}{*}{ Canon $50 \mathrm{~mm}$} & \multirow{3}{*}{$\mathrm{A} 3$} & 1 & 50.282 & 0.655 & 0.267 & 0.200 & 0.263 & 16.523 & 11.095 & 0.330 & \\
\hline & & 2 & 50.336 & 0.678 & 0.186 & 0.171 & 0.319 & 16.533 & 11.117 & 0.318 & deformation of \\
\hline & & average & 50.309 & 0.667 & 0.227 & 0.185 & 0.291 & 16.528 & 11.106 & 0.324 & the test field \\
\hline & & 1 & 70.332 & -0.603 & 0.069 & -1.559 & -9.801 & 19.850 & 10.263 & 0.250 & \\
\hline Canon $70 \mathrm{~mm}$ & A3 & 2 & 70.528 & -0.604 & 0.053 & -1.421 & -4.290 & 19.704 & 11.165 & 0.279 & \\
\hline & & average & 70.430 & -0.603 & 0.061 & -1.490 & -7.046 & 19.777 & 10.714 & 0.265 & \\
\hline & & 1 & 84.704 & -0.253 & -0.086 & -0.221 & -0.684 & 16.860 & 11.212 & 0.278 & \\
\hline Canon $85 \mathrm{~mm}$ & $\mathrm{~A} 3$ & 2 & 84.925 & -0.259 & -0.064 & -0.297 & -0.652 & 16.914 & 11.126 & 0.281 & \\
\hline & & average & 84.815 & -0.256 & -0.075 & -0.259 & -0.668 & 16.887 & 11.169 & 0.279 & \\
\hline
\end{tabular}


Performed research allowed for formulating the following conclusions:

- Image Master Calib allows for fast determination of interior orientation parameters and parameters of the camera lens distortion function,

- in case of taking photographs of a larger test field (such as A0), higher repeatability of the method if determination of the interior orientation parameters and the lens distortion parameters occurs than in case of taking photographs of smaller test fields,

- the computational algorithm of the Image Master Calib package assumes the flatness of the calibration sheet, therefore the non-flatness of the test field negatively influences the determination of values of parameters of the interior orientation and distortion,

- the small level of deformations of the test field sheet results in small decrease of the accuracy of determination of parameters of the interior orientation and distortion, and high deformations makes the determination of the above parameters impossible.

Elaboration of the results of the second experiment, which included multiple registration of the same profile, consisted of manual "cleaning of the point cloud" from noises and of presentation of data in the form of a vertical section between points $A$ and B. This step of works was performed using the Image Master and Microsoft Office Excel packages.

Besides simple fragments of column surfaces, many architectural adornments were registered in the $A B$ profile, which created convex or concave surfaces, which may result in "sliding" of the laser beam. Therefore, only three fragments, presented in Fig.5, which are approximately flat fragments of columns, were selected for further analysis. Each of analysed fragments of the profile was observed under various zenith angles.

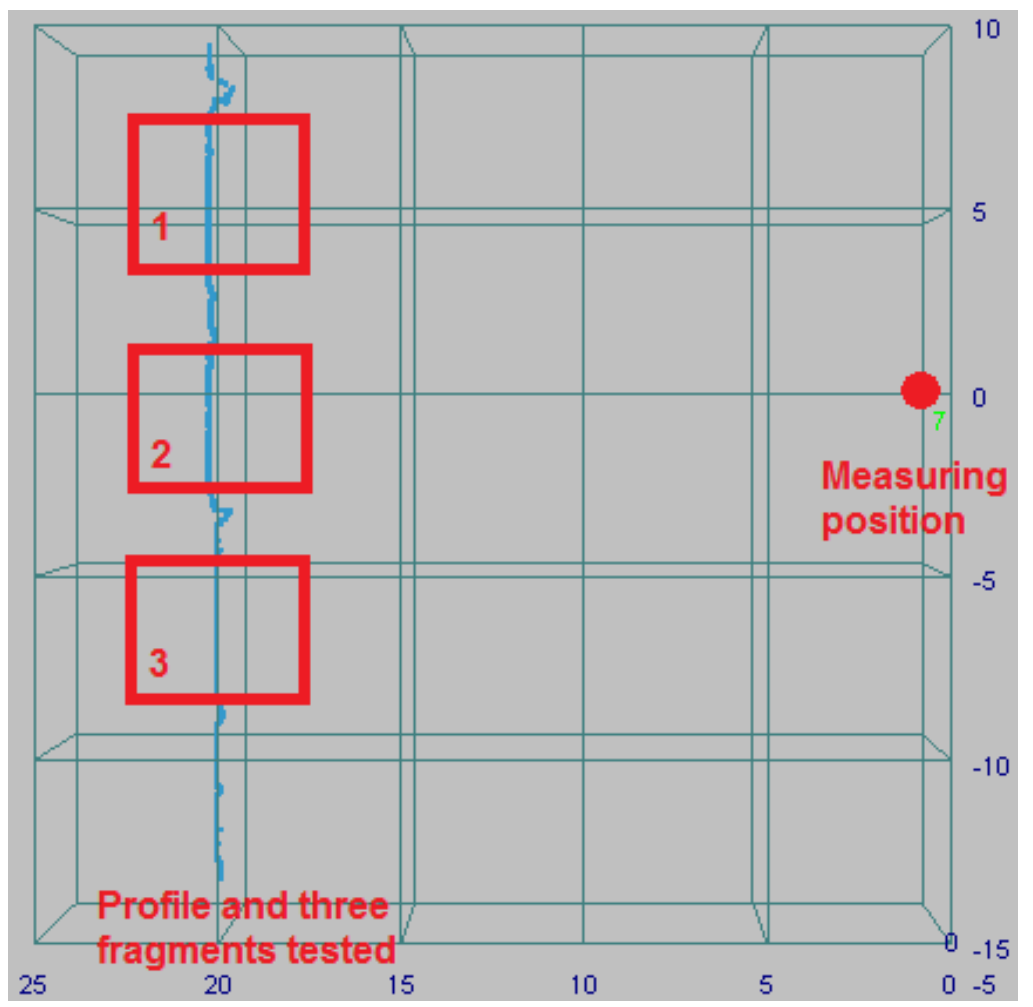

Fig. 5. A sketch of the measured profile - view of the dialog box 
The next step was the determination of average values from series of measurements for particular fragments and for particular scanning densities. The values of the average deviation of the profile from series of measurements were separately calculated for specified profile heights and they are graphically presented in Fig.6. Horizontal axes of graphs present the profile deviation from the vertical line passing through the point furthest away from the station. Due to requirements of calculations, it was necessary to interpolate values of deflection of the wall for particular levels of the profile.

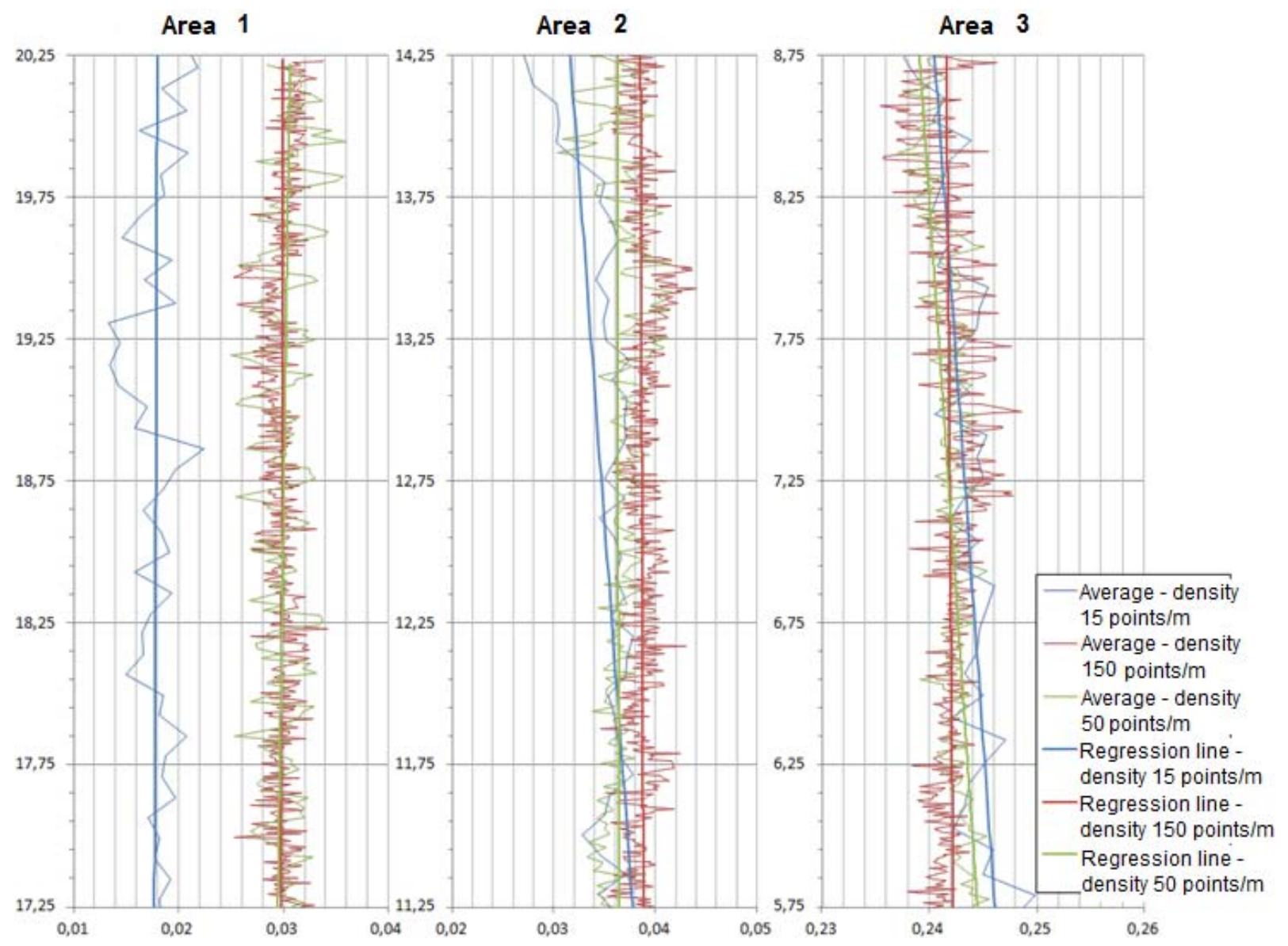

Fig. 6. Average values of observation series and the average regression lines for different scanning densities for the three parts (the vertical axis - height [m], the horizontal axis deviation in plane of alignments [m])

The values of deviations were calculated in subsequent series, with respect to various mutual references of series of observations, for various scanning densities. Interpolation was performed in two ways:

- first - calculation of deviations series 2, 3, 4 profiles scanned with a density of 15 points / $\mathrm{m}$ (and respectively the density of 150 dots $/ \mathrm{m}$ and 50 points $/ \mathrm{m}$ ) for the height of points measured during series 1 (series 1 height of points projected onto the other series );

- second - calculating deviations series 1, 2, 3, 4 scanned profiles with a density of 15 points / $\mathrm{m}$ (and accordingly the density of 150 dots $/ \mathrm{m}$ and 50 points $/ \mathrm{m}$ ) for a constant height interval. 
The values of calculated standard deviations may be considered as characteristics of the assessment of differences between the results of particular series of measurements obtained for three areas, with the use of three various scanning densities. Both methods of interpolation, with the use of the same number of interpolated points obtained similar standard deviation values (the maximum difference equal to $0.6 \mathrm{~mm}$ ). The analysis of results presented in Tab. 2 allows for formulation of the following conclusions:

- the discrepancy of results of scanning of the higher density presents the smaller discrepancy value,

- for the same density of point measurements - (15 points $/ \mathrm{m})$ various deviation values were obtained for various fragments of scanning - better results were obtained for the area 3 than for the area 1,

- similarly, for the scanning density of 50 points $/ \mathrm{m}$ - better results were obtained for the area 3 than for the area 1,

- for high scanning densities (150 points/m) - comparable results were obtained for all areas: 1, 2 and 3,

- the standard deviation decreasing systematically and caused by the angle of incidence for small scanning densities, but in the case of the density of 150 points $/ \mathrm{m}$ it is the opposite.

Table 2. Standard deviations [in $\mathrm{mm}$ ] for measurement series for particular areas of measurement using different interpolation methods in profile

\begin{tabular}{|l|c|c|c|c|}
\cline { 2 - 5 } \multicolumn{1}{c|}{} & Scanning density & Area 1 & Area 2 & Area 3 \\
\hline \multirow{2}{*}{$\begin{array}{l}\text { Interpolation basing on } \\
\text { the height according to } \\
\text { series 1 }\end{array}$} & 15 points/ $\mathrm{m}^{2}$ & 5.87 & 3.73 & 3.20 \\
\cline { 2 - 5 } & 50 points/ $\mathrm{m}^{2}$ & 2.97 & 2.19 & 1.87 \\
\cline { 2 - 5 } & 150 points/ $\mathrm{m}^{2}$ & 1.51 & 1.76 & 1.88 \\
\hline $\begin{array}{l}\text { Interpolation basing on } \\
\text { the height according to } \\
\text { series 2 }\end{array}$ & 15 points/ $\mathrm{m}^{2}$ & 5.86 & 3.81 & 3.59 \\
\cline { 2 - 5 } & 50 points/ $\mathrm{m}^{2}$ & 3.09 & 2.20 & 1.90 \\
\hline $\begin{array}{l}\text { Interpolation basing on } \\
\text { the height according to } \\
\text { series 3 }\end{array}$ & 150 points/ $\mathrm{m}^{2}$ & 1.55 & 1.78 & 1.87 \\
\cline { 2 - 5 } $\begin{array}{l}\text { Interpolation basing on } \\
\text { the height according to } \\
\text { series 4 }\end{array}$ & 15 points/ $\mathrm{m}^{2}$ & 5.63 & 3.74 & 3.56 \\
\hline $\begin{array}{l}\text { Interpolation basing on } \\
\text { the constant interval of } \\
\text { height }\end{array}$ & 15 points $/ \mathrm{m}^{2}$ & 3.10 & 2.08 & 1.83 \\
\cline { 2 - 5 } & 50 points $/ \mathrm{m}^{2}$ & 5.69 & 3.75 & 3.43 \\
\cline { 2 - 5 } & 150 points $/ \mathrm{m}^{2}$ & 2.37 & 2.07 & 3.14 \\
\hline
\end{tabular}

The next task aimed at building of a spatial model of a selected object, basing on video-tacheometric measurements performed with the use of Image Station IS-3 tacheometer and digital photographs taken with the use of Canon EOS 5D Mark II camera. Results of video-tacheometric measurements were processed by Topcon Image Master package. It allows for initial processing of "point clouds", i.e. combination and visualisation of raw observational data, elimination of unnecessary points (disturbances), supplement of missing data and creation of polylines and outlines. All corrections may be semi-automatically or automatically performed. 
The programme automatically generates the TIN mesh surface and applies the texture from digital photographs on it. However, the programmes does not "improve the appearance" of the generated model. The option allowing for smoothing surfaces and fitting selected objects to specified point clouds is also missing. The programme does not allow for automatic filtering of data or for perform complex 3D modelling functions.

As a result of data processing two models of the measured wall were generated. The TIN model was created which consisted of flat elementary triangular surfaces based on corners, which were the measured points (Fig.7). This structure is the natural model, since it is based only on surveyed data, with the possibility of intervention in distribution of points by changing parameters of the algorithm of creating triangles. The idea of Delaunay's method is applied for creation of the TIN mesh model in the Image Master system.

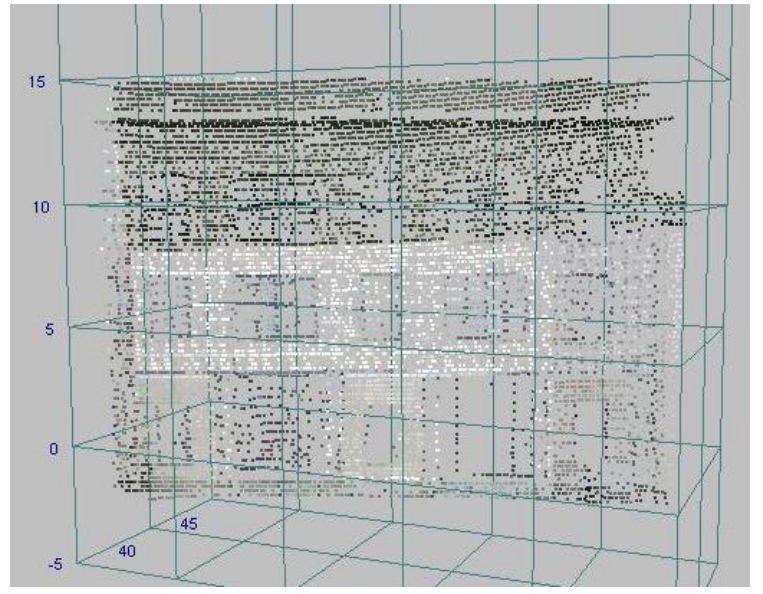

a)

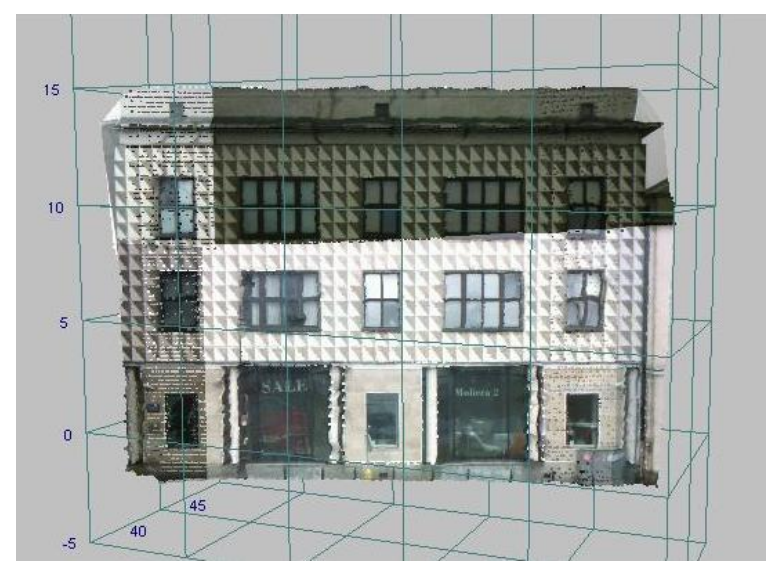

c)

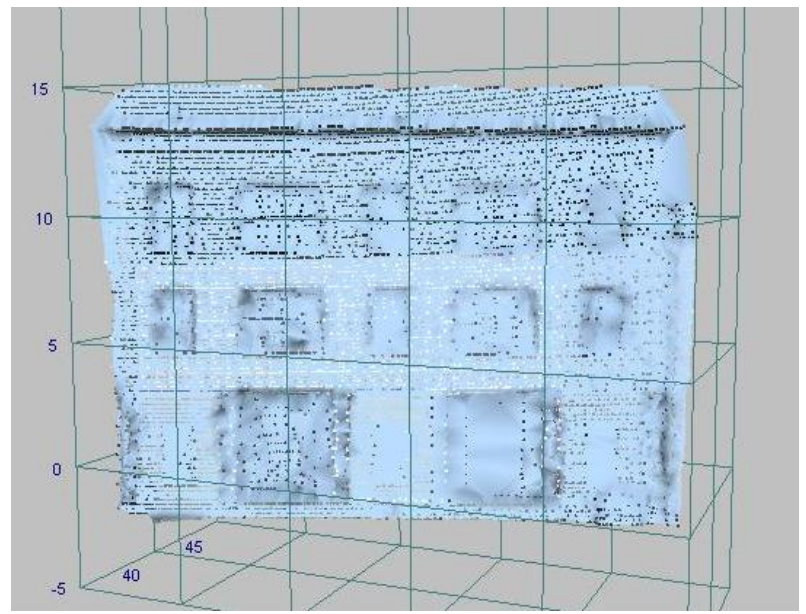

b)

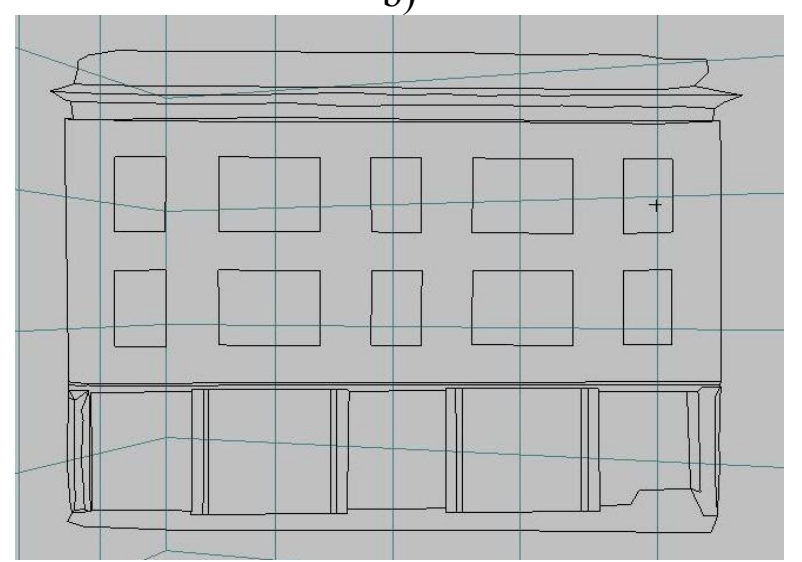

d)

Fig. 7. Steps of the spatial model building: a) visualization of the point cloud with texture applied to photographs from video-TPS, b) TIN, c) TIN of the applied texture from images taken from video-TPS, d) wireframe model created using polylines

Images acquired by means of the video-tacheometer were imposed on the created triangular mesh. Image data from photographic acquisition might be compared with "point clouds" obtained from direct measurements. Those operations turned to be very useful in the process of filtration of noises and elimination of erroneous observations (Fig. 8). 
The wireframe model (Fig. 7d), created of distinguished edges of a given object, served for comparing data at the next stage of works. It consists of polylines only (points and lines) which are often the final form of results of data processing.

Edge detection, as well as detection of discontinuities of lines of object details, detected on the basis of acquired "point clouds" form the great challenge in the case of laser scanning technology. It is possible to identify and geometrically interpret such elements, basing on point clouds, but it requires the sufficiently high mesh density. On the other hand the high density of points results in the increased size of the file and makes the explicit geometric interpretation more difficult. Software which was used for presented works, did not allow for automatic searching for the lines of discontinuity, therefore this operation was performed manually, by means of analysis of features of photographic and geometric data.

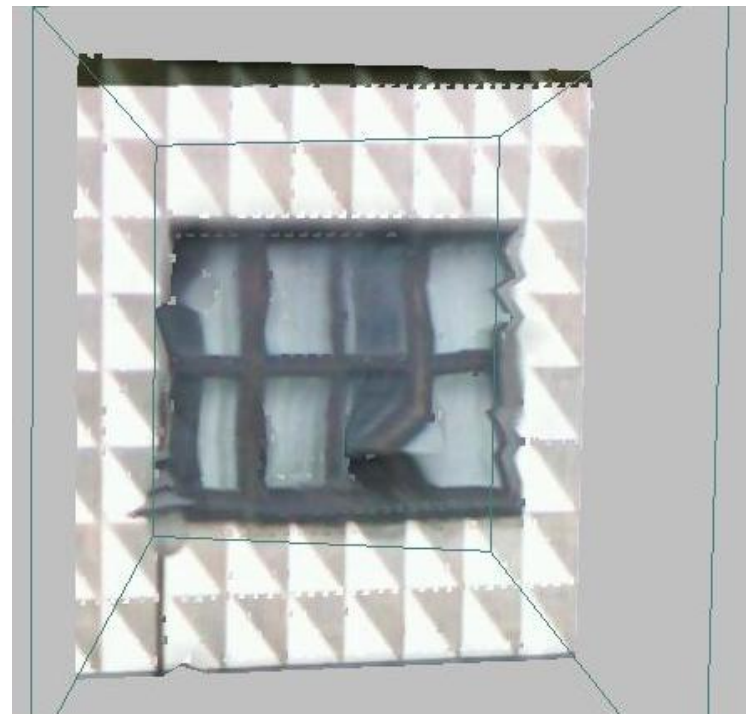

a)

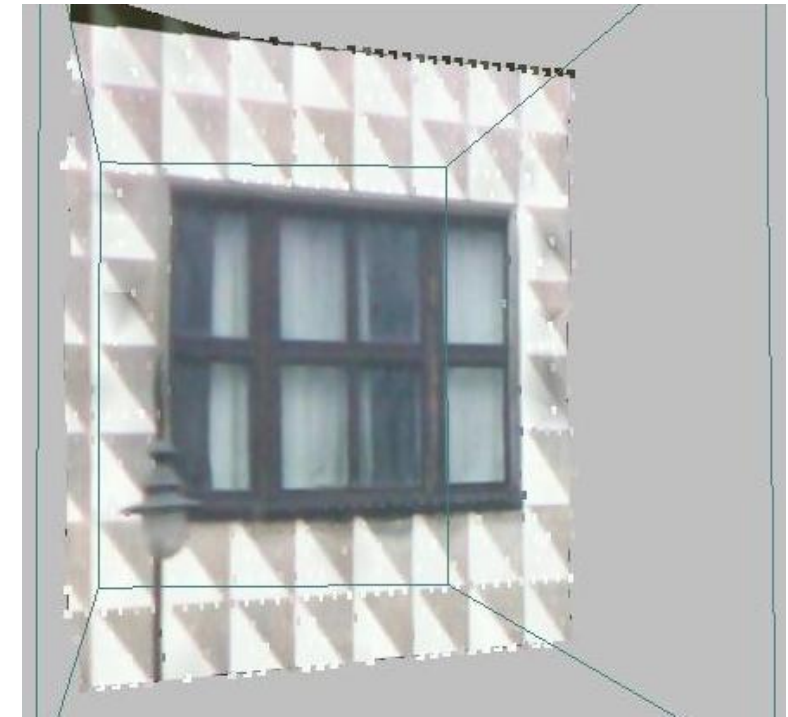

b)

Fig. 8. View the results of data cleansing: a) part of the TIN model before filtration and data cleaning from the point cloud, b) part of the TIN model after filtration and data cleaning from the point cloud

In order to obtain the high quality of images of the object, separate photographs of its fragments may be acquired with the use of a professional photographic camera. The exterior orientation of images acquired by such a camera consists of determination of relations between the photograph image co-ordinates, the coordinates of the centre of projection and angles of the exterior camera orientation with the field co-ordinates. It is performed by matching the central projection bundle of the camera into the set of field points. The exterior orientation may be performed by means of one of two methods: the bundle adjustment method, which requires the knowledge of the camera interior orientation or by means of the Direct Linear Transformation (DLT) method, based on the projection transformation, which does not require the knowledge of the camera parameters.

The method of the central projection bundle adjustment method was used for the presented works. Since co-ordinates of the matching points were not known, the well identifiable corners of black-and-white triangles, located on the wall façade, were used as matching points (Fig. 9). 


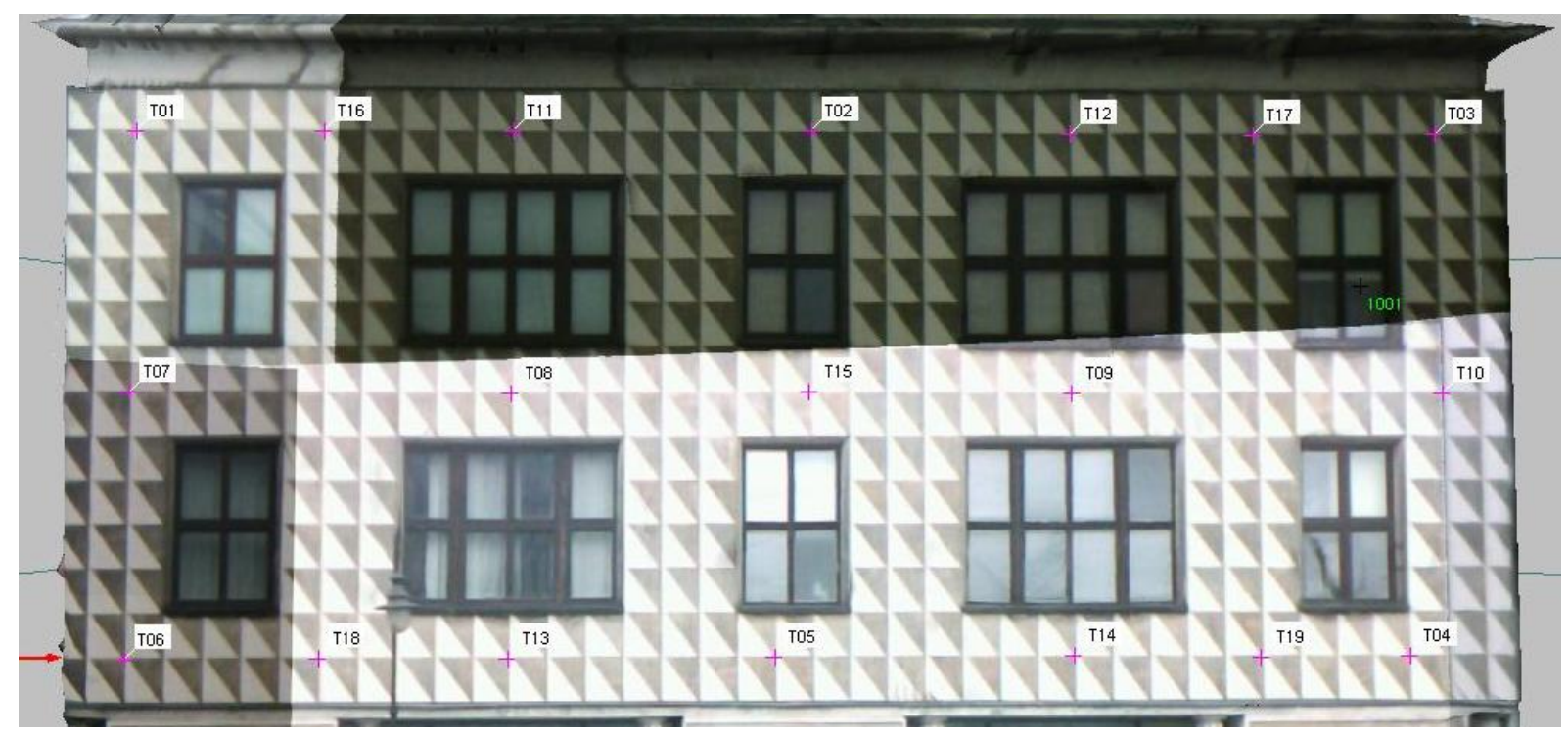

Fig. 9. The TIN Model with tie points

Table 3 presents the exterior orientation parameters and errors of matching of two photographs of different size, basing on 6, 10, 19 or 16 image points (Fig. 10 shows TIN model textured by this two photographs of different size). In the case of the lower resolution photograph (920x613 pixels) matching errors of the order of 1 pixel were obtained. The increased number of matching points did not improve this parameter of transformation, increasing, at the same time, the value of the matching error. But in the case of the higher resolution photograph (2808x1872 pixels) the number of matching points (10 and 19 image points) did not noticeably influence on the value of this error.

Table 3. The results of application of the texture on the TIN mesh from images of different sizes, by defining a different number of tie points

\begin{tabular}{|c|c|c|c|c|c|c|c|}
\hline \multirow{2}{*}{\multicolumn{2}{|c|}{\begin{tabular}{|c|}
$\begin{array}{c}\text { Size of the photograph } \\
\text { [pixel] }\end{array}$ \\
$\begin{array}{c}\text { Number of register } \\
\text { marks }\end{array}$ \\
\end{tabular}}} & \multicolumn{3}{|c|}{$920 \times 613$} & \multicolumn{3}{|c|}{$2808 \times 1872$} \\
\hline & & $\begin{array}{c}6 \text { (on } \\
\text { facade) }\end{array}$ & $\begin{array}{l}10 \text { (on } \\
\text { facade) }\end{array}$ & $\begin{array}{c}19 \text { (on } \\
\text { facade) }\end{array}$ & $\begin{array}{l}10 \text { (on } \\
\text { facade) }\end{array}$ & $\begin{array}{l}19 \text { (on } \\
\text { facade) }\end{array}$ & 16 (on edges) \\
\hline \multicolumn{2}{|c|}{$\begin{array}{l}\text { Error of photograph } \\
\quad \text { fitting [pixel] }\end{array}$} & 0.91 & 1.24 & 1.32 & 0.26 & 0.27 & 0.45 \\
\hline \multirow{6}{*}{ 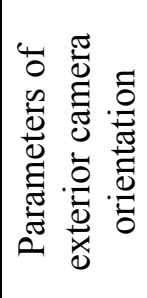 } & $\mathrm{Xo}[\mathrm{m}]$ & 49.2610 & 52.6091 & 57.0352 & 7.8271 & 6.7919 & 3.1621 \\
\hline & Yo $[\mathrm{m}]$ & 232.5525 & 233.5863 & 232.7155 & -43.6402 & -43.2379 & -43.0051 \\
\hline & $\mathrm{Zo}[\mathrm{m}]$ & 1.7730 & 2.5206 & 4.4349 & -5.6347 & -7.3858 & -5.0632 \\
\hline & omega [deg] & -84.601 & -80.562 & -81.881 & -91.990 & -93.142 & -91.744 \\
\hline & phi [deg] & -1.365 & 0.440 & -0.111 & -1.156 & -1.629 & -1.363 \\
\hline & kappa [deg] & 3.451 & 2.895 & 1.968 & -1.645 & -1.103 & 1.342 \\
\hline
\end{tabular}


a)

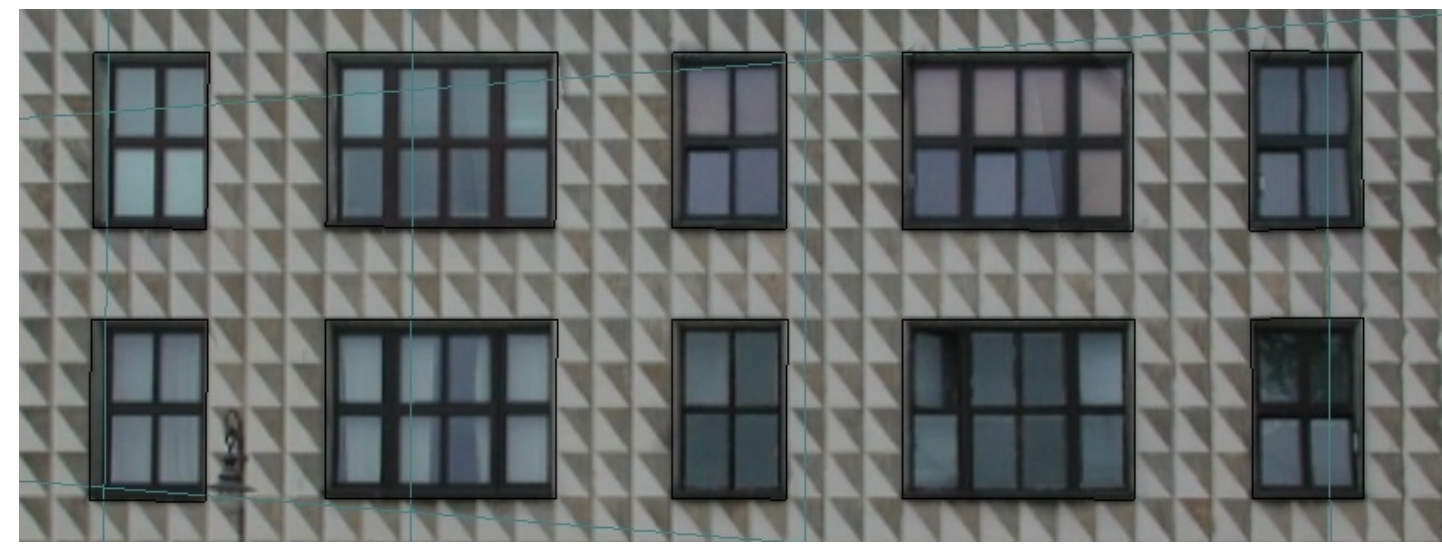

b)

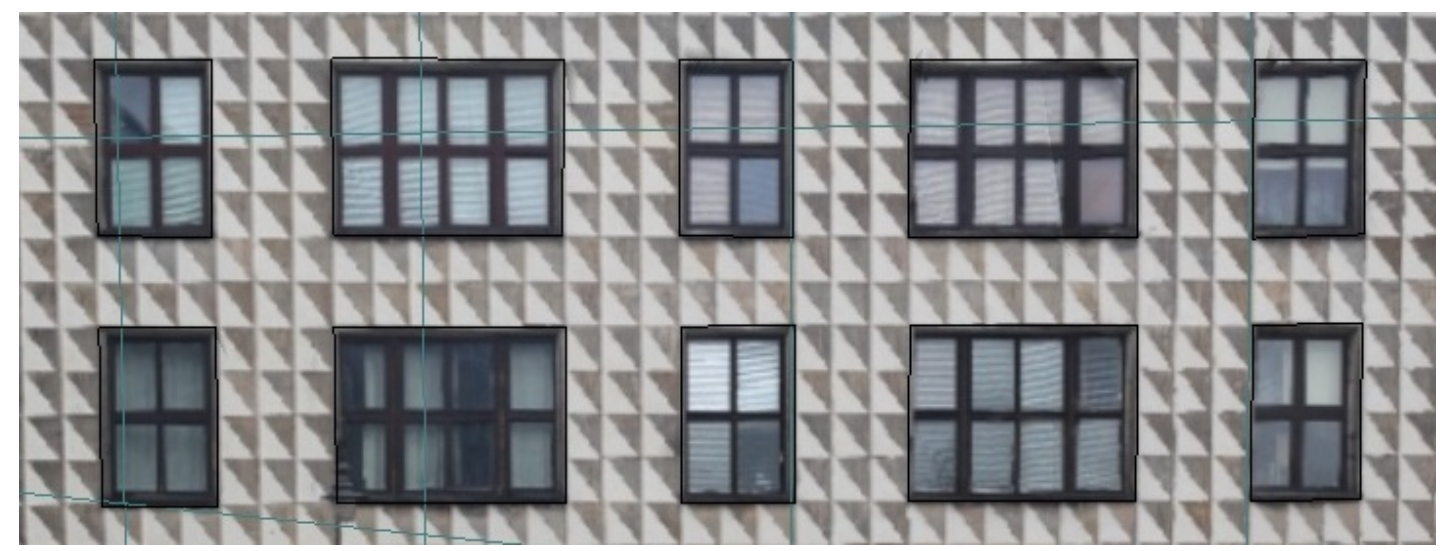

Fig. 10. TIN Model textured by two photographs of different size: a) $920 \times 613$ pixels,

b) $2808 \times 1872$ pixels

High discrepancies occur between parameters of the exterior orientation, calculated for particular photographs (Xo, Yo, Zo, $\omega, \varphi, k)$. The obtained results confirm the low stability of the photographic acquisition system and the low geometric accuracy of the data file.

\section{Conclusions}

Basing on the performed tests it was stated, that utilisation of video-tacheometric technology as a spatial data integration method for data obtained with classical technique using the tacheometer, with digital images shows high suitability for geometrical inventory of engineering objects.

Technological solutions joining in one device standard tacheometric observations $(\mathrm{Hz}, \mathrm{V}, \mathrm{D})$ with digital images correlated with an orientation system, have a lot of advantages and enable the automatic processing of registration results of observed values. It is especially noticeable in case of traditional, photogrammetric measurements supported by tacheometric surveys.

The video-tacheometers inverted the task of photogrammetric object registration, taking - as the basis for the object's model generation - precise results of tacheometric surveys performed in reflectorless tacheometric measurements mode, supplemented with digital images. Elements of these images are very well spatially correlated with the "wireframe" of the object's model. This technology is characterized by the uniquely high effectiveness of both types of data collection. Comparing to the method based on separate collection of digital images and "point 
clouds", video-tacheometric technology is much less survey time-consuming and is characterised by the absence of identification errors and by automation of the entire development of the measurements process. The "point clouds" integration process with digital images taken with an independent camera was evaluated as ineffective and susceptible to occurrence of identification errors.

During research works on this technology the existence of several system measurement limitations was stated. They are caused by the limited speed of tacheometric measurements (in theory up to 20 points per second), as well as by the registered images resolution. Both elements are not so excessive and probably will be improved in the future versions of this instrument. These are crucial limitations in case of this technology utilization in processes of monitoring shifts of engineering objects.

The important disadvantages of this measurement system are scanning limitations in LINE mode to the vertical plane only in "up - down" direction. The other inconvenience is the possibility of working during scanning process in one position of the vertical circle only. These limitations have different reasons and in our opinion may be easily eliminated in the future versions of this instrument.

The Image Master measurement data processing system and its software segments also have significant limitations.

During the research much attention was paid to the detailed functional analysis of Image Master Calib. This system is efficient in operation; unfortunately its algorithm's resistance for the test field deformation is low. Determined calibration parameters of the digital camera demonstrated high sensitivity for the test field geometry, leading to the impossibility of calibration parameters determination in case of high deformations of calibration sheets. Taking this into account, the camera calibration process should be performed with the use of flat test field, high accuracy of its realization and rather big format size. Much better results for the same camera were obtained in case of A1 format calibration sheet than for the A3 sheet.

Additionally, the depth of field limitations caused significant deterioration of determination of the camera calibration parameters. In case of independent, external camera utilization, high definition CMOS matrices and professional photographic lenses with good projection quality should be used.

Multiple scanning of a chosen column profile showed repeatability of measurement results in the range of $6 \mathrm{~mm}$. However, it was noticed that for higher scanning resolutions differences existing between measurement series of the same element were significantly smaller. It suggests the existence of some correlations of distance measurement results.

The video-tacheometric technology needs to be improved in its all fields. However, it delivers several beneficial features, which can be used in automated inventory surveys of moderate accuracy requirements.

\section{References}

Bernasik J., 2006. Zdjęcie fotogrametryczne. Fotogrametria. Photogrammetric images. Photogrammetry. Uczelniana Platforma Learningowa, Kraków, 16-34.

Kurczyński Z., Preuss R., 2003. Podstawy fotogrametrii. Oficyna Wydawnicza PW, Warszawa.

Owczarz A., 2004. Fotografia cyfrowa. Digital photography, HELION, Gliwice. 
Piasecki M., 1958. Fotogrametria lotnicza i naziemna. Aerial and terrestrial photogrammetry. PPWK, Warszawa.

Sitek Z., 1991. Fotogrametria ogólna i inżynieryjna. General and engineering photogrammetry, PPWK, Warszawa-Wrocław.

Sitek Z., 1984. Elementy fotogrametrii i fotografii technicznej. Elements of photogrammetry and technical photography, PWN, Warszawa.

Tkaczyk E., Szumowska E., Woźniak M., 2011. The use of video-tacheometric technology in the construction of the spatial model of an object. Raports on Geodesy 1(90). Oficyna Wydawnicza PW, Warszawa, 495-502.

Tkaczyk E., Szumowska E., 2010. Wykorzystanie video-tachimetru do budowy przestrzennego modelu obiektu. Using a video-tacheometer to create a spatial model of an object, Praca dyplomowa magisterska.

Woźniak M., 2005. Bezreflektorowe systemy pomiarowe w monitorowaniu przemieszczeń. Bezdotykowe metody obserwacji i pomiarów obiektów budowlanych. Instrukcje, wytyczne, poradniki 443/2009. Reflectorless measuring systems in monitoring of displacements. Contact-free methods of observations and measurements of constructions. Instructions, guidelines, manuals 443/2009. Instytut Techniki Budowlanej, Warszawa, 127-135.

Woźniak M., Anioł P. 2011 Inventorying the shape of a velodrome track by scanning Reports on Geodesy - Warsaw University of Technology - No 1(90) Warszawa, 525-530)

Woźniak M. 2011 Geodetic inventory of a cooling tower using reflectorless technique - Reports on Geodesy - Warsaw University of Technology No 1(90) 2011 Warszawa, 515-524

Woźniak M., Woźniak K. 2011. Geodetic measurement methods and shape estimation of concrete thin shell surface - Reports on Geodesy -EGU VIENNA Warsaw University of Technology - No 2(91) Warszawa, 81-88

\section{Authors:}

Marek Woźniak ${ }^{1)}$,Ph.D.Eng., m.wozniak@gik.pw.edu.pl

Ewa Świerczyńska ${ }^{1)}$, M.Sc., e.swierczynska@gik.pw.edu.pl

Sławomir Jastrzębski ${ }^{1)}$, Ph.D., s.jastrzebski@gik.pw.edu.pl

1) Faculty of Geodesy and Cartography

Warsaw University of Technology

PI. Politechniki 1, 00-661, Warsaw, Poland 